\title{
O AND É JOGO? ENSAIO-CONVERSA À VOLTA DA OPERACIONALIDADE DO JOGO NO MODO OPERATIVO AND
}

Fernanda Eugenio ${ }^{1} \&$ Ricardo Seiça Salgado AND Lab, Rio de Janeiro, Brasil / CRIA-UMinho, Coimbra, Portugal

O Modo Operativo AND (MO_AND) é um sistema de improvisação e com-posição-com que oferece um conjunto de instrumentos para o estudo praticado das politicas da convivência e das capacidades de auto-observação em ato e de tomada de decisão situada. No MO_AND, o (contra)dispositivo do jogo não-competitivo é usado como "simulador de acidentes". Trabalhando com escalas de menorização/maximização do (in) visivel e de reduçãolampliação do espaço e do tempo, o jogo AND permite frequentar a atenção ao comum, a disponibilidade ao imprevisto e o prazer da comunidade, articulando-se como convite a uma investigação experiencial dos funcionamentos e (des)dobramentos do Acontecimento - seja no acompanhamento da sucessão espiralada das suas emergências e esgotamentos, seja através do manejo direto da sua propagação em regras imanentes e sempre provisórias. Neste ensaio-conversa, Ricardo Seiça Salgado - a partir da sua investigação sobre os procedimentos e efeitos do jogo performativo com e na etnografia - e Fernanda Eugenio - que vem desenvolvendo o MO_AND numa trajetória de contaminação recíproca entre a antropologia e a performance - experimentam percorrer a paisagem de questóes suscitadas por esta investigação, colocando em perspetiva o seu legado e potência enquanto jogo.

Palavras-chave: modo operativo AND, jogo, nonsense, etnografia, comum, ética da suficiência

1 Contato dos autores: fe.eugenio@gmail.com / ricardoseica@gmail.com 


\section{O joGo}

A conversa que aqui se publica resulta de uma proposta que o Ricardo faz à Fernanda. A pergunta se o Modo Operativo AND é jogo levou-nos a produzir previamente à conversa um texto em que o Ricardo explicaria o que se poderá entender por jogo e a Fernanda o que se entende por MO_AND. A leitura recíproca dos textos funcionaria como gatilho para a conversa, desenhando também o campo de forças a percorrer. O primeiro texto incorporou-se na introdução deste dossiê, "Para uma definição de jogo", o segundo encontra-se disponível no AND Doc, Acervo Digital do AND Lab, sob o título "Para uma situ-ação do Modo Operativo AND” (Eugenio 2018). Na última rodada da conversa, invertem-se repentinamente os papéis e é a Fernanda que pergunta ao Ricardo porque é que o MO_AND é jogo.

\section{Modo Operativo AND EM 10 Posições}

1. As "regras" deste jogo emergem do próprio jogar. Condição para as encontrar: a) inibir o hábito de querer perceber, de tentar compreender, de julgar saber; $b$ ) ativar a sensibilidade do "saborear", isto é, deixar que seja o acontecimento a manifestar ao que sabe. Numa frase: substituir o "saber" pelo "sabor".

2. O jogo começa quando o inesperado irrompe. Quando se dá um acidente. Perante o vazio que se instala: fazer nada. "Fazer nada" não é parar - estacar, paralisar - mas sim re-parar $($ re = repitação), ou seja, voltar a parar para reparar (perscrutar).

3. Enquanto "faz nada", repare onde está, no que há à volta, no "Quê" daquilo que se apresenta - este "Isso" inominável que o acidente manifesta, a cada vez, como "Isto" singular. Repare também naquilo que tem para oferecer, na condição de se encaixar no acontecimento.

4. A haver um único objetivo neste jogo é conseguir a transferência do protagonismo do sujeito para o acontecimento. Essa transferência dá-se substituindo as perguntas habituais do sujeito - quem e porquê - com as interrogações que o acontecimento nos coloca: o quê, como, onde e quando. Pergunte à situação que se apresenta: $\mathrm{O}$ quê, no que aí está? Como, com este quê? Onde-quando, com este como?

5. Para participar no jogo, não tente contribuir tendo um fim em mente e muito menos tendo o início como ponto de partida. Este jogo começa sempre pelo meio.

6. As regras são encontradas após um mínimo de 3 tomadas de posição e 2 entradas em relação: a) A primeira posição oferece o meio no qual reparar; b) A segunda posição entra em relação com a matéria oferecida pela primeira, sugerindo uma direção; c) A terceira posição entra em relação com a relação sugerida pela segunda, confirmando uma direção partilhada, o plano comum.

7. Uma vez encontrado o plano (geométrico) comum - um sentido-direção e não um sentido-significado - jogar o jogo é adiar o fim. Única tarefa: sustentar a vitalidade desse plano através do manuseamento das doses de diferença e repetição introduzidas na relação a cada momento. Condições para se adiar o fim: aceitar o fim e antecipar o fim. Aceitar a "finitude", 
de modo a trabalhar pela "ilimitude"; antecipar os sinais de "finitude", de modo a usa-los no manusear da "ilimitude".

8. Este é um jogo de perguntas silenciosas: cada jogada é oferecida e recebida sem resposta, explicação ou interpretação. Para que as tomadas de posição possam dispensar justificações, precisam de ser, ao mesmo tempo, abertas e completas (e não fechadas e incompletas) e explícitas e consistentes (e não implícitas e coerentes).

9. O Jogo AND, se for jogado segundo os princípios aqui enunciados, nunca termina. A não ser que seja interrompido por um acidente.

10. Nesse caso, pare, repare e volte a jogar.

\section{$\mathrm{O}$ «NONSENSE» E AS REGRAS DO MO _ AND}

RICARDO - Todos os jogos necessitam de regras. São elas que nos forçam a sair das lógicas da vida e a entrar na esfera do jogo que nos passa a jogar (Gadamer 1999). Brian Sutton-Smith (2001) diz-nos que o nonsense, a jocosidade (playful), o espírito brincalhão, é o mais profundo caráter do temperamento do jogo. Ele é o resultado do uso de um conjunto de procedimentos interpretativos. Apropria-se de uma organização de categorias do senso comum e atravessando essa organização através de procedimentos de reversão ou de inversão, muda as fronteiras dessas categorias, repete-as até ao infinito, até à exaustão, conjugando-as no tempo, ou fraturando-as nos seus membros, recombinando-os de acordo com algum princípio, reinventando as lógicas (Stewart 1989: 199). Como tática que é, o nonsense é uma ação calculada que não tem por lugar senão o do outro, há uma ausência de um próprio e, por isso, "deve jogar com o terreno que lhe é imposto tal como o organiza a lei de uma força estranha" (Certeau 1998: 100).

O nonsense confronta os procedimentos do senso comum e funciona questionando, criticando, subvertendo-o para criar mundos outros possíveis. Elizabeth Sewell (2015: 1) diz que o nonsense não depende da aceitação ou rejeição de certos factos, mas sim da adoção de um certo conjunto ou tipo de relações mentais. É definido como uma coleção de palavras ou eventos que, em seu arranjo, não encaixam num sistema mental reconhecido (ibidem). Então, nonsense é mimese-jogo. Quando o nonsense constitui o temperamento do jogo (como na improvisação e experimentação artística, ou na vida quando enfrentamos novos desafios), há uma descentralização das lógicas de relacionamento e de encontro. $\mathrm{Na}$ arte, estará relacionado com a reinvenção dos procedimentos artísticos, pelo menos, dos modos de improvisação. O nonsense é um transgressor e constitui-se a si próprio enquanto profanação (Agamben 2007). Como sugere Agamben, o jogo neutraliza o que profana e devolve ao uso comum o que o poder havia confiscado (ibidem: 77).

Para jogar o AND é preciso disponibilidade para sair do "modo operativo É, aquele que governa o senso comum, e de todos os seus dispositivos reguladores do comportamento que definem a interpretação, a representação, o imperativo do significado, como dizes. Por outro lado, é sempre sobre o acontecimento que interrompe o nosso nexo a que chamas de "acidente", esse "outro" sob o qual o jogador toma a sua posição na relação, definindo-se a sua atenção ao 
longo do acontecimento mas desprendida das lógicas do "Modo Operativo É”. Pergunto se essa não será uma regra fundamental do jogo AND, senão mesmo a regra do jogo para que aconteça esse "murmúrio de acidente-e-improviso, tentativa e erro, que vai sendo a matéria e fazendo a consistência das nossas relações” (Eugenio 2017: 204), e que permite o jogo funcionar. Se para o jogo fluir é pressuposto aceitar o acidente, ou a interrupção do que é expectável comumente para cada um de nós no encontro com os outros jogadores, não será que há um chamamento ao temperamento do nonsense enquanto atitude que o jogo convoca para fazer perdurar o MO_AND?

FERNANDA - Interessante voltar a formular o AND entrando pela porta do nonsense nunca havia pensado nestes termos. De facto, o AND convoca um "espírito brincalhão", talvez até em mais de uma valência: pede por disponibilidade e abertura, mas também por uma prontidão ao desapego, por leveza no deixar-se levar, por uma atitude simultaneamente de desinteresse interessado e interesse desinteressado. Ativa-se, assim, enquanto tática de des-autorização - desinvestimento no sujeito-autor e transferência do protagonismo para o acontecimento - e des(a)propriação - desinvestimento no agir em "causa própria" em prol do fazer-com aquilo que se apresenta, abrindo espaço para um funcionamento por co-passionamento (Eugenio 2017), em sintonia com o impróprio e o alheio.

A sensibilidade ao acidente, que funciona como condição de possibilidade para a ativação do Modo Operativo AND, não é outra coisa senão uma capacidade infinitesimal de deteção de fissuras no sentido: momentos em que este é interrompido ou suspenso, negado na sua eternidade e inteireza, seja pela súbita colisão com um sentido outro, seja pela intromissão em vislumbre do imponderável, do informulável, do impensável. De modo que se poderia mesmo dizer o acidente como materialização concreta do nonsense - a sua aparição enquanto consistência que se impõe à coerência. E, levando mais além este pensar-com o conceito do nonsense, se poderia experimentar ainda re-dizer o jogo proposto no AND - jogo de sustentação do não-saber enquanto exercício de sustentação deliberada do nonsense.

Mas talvez seja então preciso, a esta altura, clarificar o que estamos a entender por sense. Pois o AND propõe um compromisso com o desviar do sentido enquanto significado - um adiar o mais possível do fechamento que este inevitavelmente instaura: passamos então a saber, emerge o enquadramento apaziguador, a vida se re-insere no domínio domesticado do (bom-)senso - mas o faz ativando um outro sentido do sentido: o sentido enquanto direção. Jogar o jogo, no AND, não é negar o sentido, mas negar um sentido do sentido, exercitando uma abertura para que a sua estruturação se possa dar a partir de outro repertório. No lugar do significado (e da representação, e da intenção), experimentar (n)a faixa de frequência em que o sentido se manifesta como tendência, inclinação. $O$ chamamento é para uma brincadeira, sim, mas séria e rigorosa, estritamente geográfica, um exercício de rastreamento descritivo (Latour 2005): a de seguir de perto em perto o acontecimento conforme ele se (des)dobra, verificando, a cada jogada (co-posicionamento), para onde ele tende, se inclina e se dirige, ou como ele se re-posiciona, perfazendo aos poucos uma paisagem toda feita de relevos emergentes.

Visto desta perspetiva, o jogo AND estaria a propor, então, o habitar do nonsense - ou, mais precisamente, de um não ao sentido (não ao significado, à relevância, à coerência) - através do performar de um sentido outro (aquele da direção, do relevo e da consistência). No AND começa-se pela irrupção do nonsense, mas somente se pode continuar pelo encontro de um 
sentido por onde seguir, uma direção comum. O não ao sentido é inaugural, mas não definitivo. Arriscaria re-propor, assim, que talvez haja mais performance de dis-senso que de não-senso na ética desse jogo, uma vez que mesmo o não ao sentido é provisório, é um adiamento: adiar o fim, porque "vivemos juntos enquanto adiamos o fim" (Eugenio e Fiadeiro 2012). Funciona, assim, sobretudo como recurso para que se possam encontrar regras imanentes, chegando ao sentido ao invés de partir dele.

Ocorre-me uma hipótese: haverá (já) uma operação de jogo entre a emergência do nonsense - a aparição do acidente - e a sua transformação em não (provisório) ao sentido. Mais ou menos o mesmo movimento que faz do acidente, acidente - tal como formula Deleuze n' A Lógica da Sensação (Deleuze 2007): o acidente precisa de ser percebido como tal - acolhido, notado, reparado - para terminar de acontecer, para tornar-se o que já era, emergindo enquanto campo de potência para contornar o cliché. Assim, embora o nonsense seja literalmente fundamental para disparar o jogo AND - funda a possibilidade de ativar a vida como jogo, e abre, por decorrência, a hipótese do $\mathrm{E}$ - penso que o faça, a princípio, sobretudo enquanto rasgo (brecha, vislumbre, insight) e não enquanto regra. A sua aparição funciona como uma chave de portal para uma dimensão paralela - a do "como se". Sinaliza a possibilidade da profanação tal como proposta por Agamben, como sugeres. Sinaliza a possibilidade de ativar uma operação de des-transcedentalização, de devolução ao plano do uso, da talvez emergência de uma geo-ética, ética de experimentação incessante e situada de táticas oblíquas - tal como o ritornelo, segundo Deleuze e Guattari (1980). Mas, sendo uma condição para abrir essa possibilidade, a sensibilidade ao nonsense não chega, da minha perspetiva, a ter a estrutura condicionante da regra, pois por si só não pode assegurar que o jogo que se instalara a seguir será AND. Diria, por isso, que encarna uma das condições do jogo - a da awareness -, precisando de se combinar com mais duas condições - a da equanimidade e a da suficiência - para conformar o campo no qual o AND se passa (ou não) a cada vez.

O jogo com o nonsense - tal como o jogo desencadeado, segundo a conhecida formulação de Vilem Flusser, pela poesia - "aumenta o território do pensável, mas não diminui o território do impensável” (Bernardo 2011: 19). Tende a operar, portanto, por proliferação e espalhamento horizontal, e não por colonização, conquista, sedimentação e progressiva domesticação do impensável - como o faz o jogo por excelência do Sentido, aquele que configura e reitera o Modo Operativo É da cosmovisão ocidental moderna. Já só por este movimento há de se reconhecer o campo de potência que instaura: aquele da liminaridade, da possibilidade de brincar com os limites e ilimites das coisas, de questionar a univocidade do sentido, ampliando-a. Mas há aqui também um risco: o da banalização por excesso, o da instauração de um jogo de "tanto faz", tão arbitrário quanto o sentido unívoco que se acabara de questionar, agora apenas pluralizado num OU, OU, OU. Talvez seja esta a vocação mais imediata do nonsense, e a tendência para a qual escorre: vir a reduzir-se a uma mera pluralização do É, ao eventualmente instalar a própria ambiguidade como modo de vida.

Será talvez por isso que, para adentrar no território do AND, importe trabalhar intensivamente para que a potência de proliferação sinalizada pelo acidente/nonsense se dê por multiplicação, não por pluralização, efetuando antes uma sensibilidade à ambivalência das coisas que uma vida assente ambiguidade, o que seria incompatível com o instalar da confiança, liga da reciprocidade. Importa, então, fazer a passagem do nonsense, que emerge com(o) acidente, ao não ao sentido, ou seja, sobretudo um retroceder da ideia, do já sabido. Uma oportunidade para não começar pelo sentido, mas pelo insosso da não-ideia, tal como a formula Jullien (2000): 
simples e desarmada sensibilidade à multiplicidade de valências presentes em cada encontro, sem ainda saber, sem ainda querer, sem ainda preferir. Tomar, então, posição-com esta matéria - a da ambivalência -, performando suficientemente uma das valências a cada vez: não todas ao mesmo tempo, o que tenderia a gerar fragmentação; não qualquer uma ou a que se quiser, mas justo aquela, materialização da des-cisão equânime. Começar assim, aos poucos, a tomar um sentido: arrumar, tomar rumo, seguindo o fio em espiral de um sentido-direção comum.

Ou seja, parece-me que há um potencial de sabedoria que se abre no encontro com o nonsense, mas que também se pode esvair se se faz dele matéria de entretenimento, profusão aleatória, descompromisso - usando o vocabulário AND, tender-se-ia aí a utilizá-lo como terreno para a ativação de um Modo Operativo OU, frequentemente confundido com o $\mathrm{E}$ - por trabalharem, ambos, com a matéria da (re)abertura do sentido -, mas completamente diverso, já que instaura o relativismo, não a relatividade. O AND, por sua vez, propõe-se num plano de reinvenção do entretenimento enquanto cuidado, pesquisando formas de performá-lo como um entre-ter: um termo-nos uns aos outros, sustentando-nos reciprocamente, eis o modo como se formula aqui o problema do "como viver do juntos" (Barthes 2003). Para tornar isso possível é de facto preciso ter regras, como bem sinalizas na tua questão, pois para haver encontro é preciso haver território, e são as regras que delimitam e perfazem um território. Mas para tornar isso possível é também preciso não as ter, ou pelo menos não as ter à partida, senão serão elas a nos terem a nós, e a confiscarem o próprio potencial de performatividade do encontro.

A nossa relação com as regras funciona a maior parte das vezes dentro de um Modo Operativo É, mais do que de um Modo Operativo AND. Ou seja, as regras pré-existem às relações, prescrevem as condutas e fornecem um quadro de valores mais ou menos fixo que sentencia de antemão o que pode um e cada corpo. As regras respondem, não perguntam. E estão mesmo desenhadas para, preferencialmente, inibir a emergência de perguntas. Regras assim produzem uma sensação de falta permanente e insuperável, uma vez que fixam modelos médios e abstratos para a ação, perante os quais cada pessoa, enquanto agregado singular, parece já começar qualquer plano de relação "em dívida" para com um "deve ser" em relação ao qual se está sempre aquém ou além. Perante este tipo de organização da vida, que pré-legisla sobre os corpos, os afetos, os encontros e as potências antes que se manifestem, temos apenas a escolha binária do obedecer ou do desobedecer, do acatar ou do contestar - sendo que ambas estas supostas "escolhas", não só não o são, por já estarem previstas no próprio script da regra, como tendem a corroborar, mesmo que pretendam o contrário, para um esquema reiterativo, que reproduz e perpetua as estruturas de poder - que vai, inclusive, anexando os territórios de contestação passados como alíneas do previsível. E isto porque quase todas as nossas regras sociais se organizam de modo transcendente. São sentenças fechadas, apoiadas em critérios implícitos, que quase sempre não são feitas por aqueles que nelas estão implicados. Ainda quando isto se dá, vez por outra - quando certas lutas sociais logram a conquista de um direito, por exemplo - este não se torna regra sem cumprir o mesmo percurso de se transcendentalizar e, por consequência, se generalizar, e passar a prescrever. Legislar não é cuidar. E não se ativa o cuidar meramente contestando as regras, ambiguando-as por pluralização. $\mathrm{O}$ cuidado envolve criar as condições para a emergência de regras, não como palavras de ordem, mas como comprometimento situado: espirais de frequentação regular de um mesmo problema, que se inscrevem sem prescrever, recorrem sem remontar, pois logram se manter abertas e serem refeitas a cada vez, num constante ajustar ao uso que se faz delas e às circunstâncias singulares que vão emergindo da participação coletiva. Regras imanentes emanam das condições oferecidas por um problema partilhado, e de um trabalho duro e dissensual de enunciação, através do qual se vai delimitan- 
do um território provisório com-possível, sem o qual o "juntos" não se passa. Elas enunciam o próprio território comum, mas o fazem enquanto pergunta e não enquanto resposta. Regras transcendentes, ao contrário, são rijas e coercitivas; são respostas prontas às quais passamos a dever - no duplo sentido da palavra.

\section{AS FUNÇÕES DO MO _ AND}

RICARDO - É interessante pensar a operatividade do nonsense como ativador ou gatilho de regras imanentes que vislumbram o comum enquanto pergunta. Cria-se um território provisório de dis-senso onde se abrem portas para além das lógicas do senso e, portanto, vive-se o espaço da liminaridade que resultará numa tomada de posição fora dessa lógica. Ao fazer da regra uma brecha ou insight, talvez o nonsense seja uma meta-regra que cria as condições para as regras transcendentes (prescritivas e reguladoras das lógicas dominantes) não se fixarem no jogo. Terão, como dizes, de nascer regras imanentes e provisórias, enquanto comprometimento situado, aquelas que você refere resultarem da emergência de um plano comum consistente do encontro entre os jogadores. Para evitar que se propague no jogo o vírus do MO_AND ou a lógica do OU e do É, é igualmente importante saber claramente quais os objetivos do MO_AND? Podemos dizer que o objetivo é o treino das práticas da atenção para a produção de comuns situados (porque somos feitos de outro e é na relação in situ que a vida se faz)?

FERNANDA: Sim, parece-me justo. O recurso à "engenhoca performativa" do jogo prende-se ao propósito de que a investigação possa ser experiencial, relacional, situada, coletiva e inclusiva, i.e. acessível para qualquer interessado. Todos os exercícios dedicam-se à afinação da escuta e da presença com uma sensibilidade ao político; ao treino das capacidades de distribuir e (re)situar a atenção como vias para o engajamento no comum. Talvez se possa dizer que o objetivo/compromisso desta prática seja, em suma, assegurar que investigar o comum não seja diferente de viver o comum: tanto porque se coletiviza o próprio ato de pesquisar (todos os implicados no problema do "juntos” são também os implicados na sua investigação), quanto porque se o torna parte contemporânea do viver (pesquisa-se o "juntos" enquanto também se o negoceia, performa e constitui). Por um lado, trata-se de transversalizar e "reciprocizar" o gesto investigativo, procurando modos de eliminar concretamente uma diferença (mais para descompasso hierárquico) que tende a ser recorrente nas investigações, apesar de tudo o que já se disse e se discutiu sobre o assunto: aquela entre pesquisador e pesquisado, sujeito e objeto, antropólogo e nativo (Viveiros de Castro 2002). Por outro, trata-se de um esforço por fazer (com os) conceitos, explorar a sua performatividade, testar a sua pertinência no plano do uso e a partir de uma abordagem que os experimenta enquanto ferramentas - algo que serve para fazer-com, não apenas para falar-sobre. Um esforço por dar a ver, através de uma prática no/com o terreno e o corpo, a distância que frequentemente persiste entre o posicionamento teórico-discursivo e aquilo que se performa-pratica no (e como) mundo, para, quem sabe, encontrar maneiras de a colmatar, fazendo co-incidir em ato o pensar e o fazer.

Não ousaria dizer que se trata de um objetivo, mas nisso tudo há o desejo de contribuir, mesmo que numa escala ínfima, para ativar anticorpos contra as formas hegemónicas da subjetividade, apoiadas numa lógica de privilégios e desprivilégios implícitos; de consumo e descarte; 
de avidez insaciável e volúvel; de um excesso desmedido e inconsequente, entretanto gerador de uma contraditória sensação de falta permanente; de um auto-centramento competitivo paradoxalmente orientado por modelos prontos e sempre externos ao sujeito. Neste sentido, o MO_AND deseja-se enquanto prática que permita sintonizar com outras formas de vida para além daquela, predominante nas sociedades capitalistas. Trata-se, claro, de um construtivismo permanente, sabedor da elevada improbabilidade senão de êxitos microscópicos e contingentes. Mas estes operam-se. Nestes cerca de quinze anos de investigação, tenho testemunhado que o praticar constante do MO_AND produz transformações sensíveis na direção de um maior descentramento e disponibilização, de uma micro-afinação da atenção, e de uma sintonização mais imediata e clara com as possibilidades cambiantes do entorno. Por consequência, vai tomando corpo uma maior habilidade para a gestão autônoma das ecologias emergentes daquilo que se faz, uma tendência mais constante ao gesto consequente e ao comparecimento voluntário no plano do cuidado coletivo, capazes de dispensar o poder centralizado, a palavra de ordem e o modelo anterior à vivência. Não me parece haver um outro modo viável para produzir mudança efetiva - em especial diante das macro-estruturas sociais que privilegiam o comportamento reiterativo - do que despertar a sensibilidade para o potencial fractal dos pequenos-grandes jogos que podemos jogar, a cada vez, de perto em perto, nos nossos próprios co-posicionamentos.

\section{A EXPERIÊNCIA DE JOGAR UMA SOCIEDADE SEM ÓRGÃOS}

RICARDO - O MO_AND, em certa medida, operacionaliza uma prática anárquica, no sentido da possibilidade de convivência sem a autoridade. Podemos até entender o MO_AND como uma pedagogia radical, na medida em que surge como uma oportunidade para superarmos a experiência de estar pseudo-juntos (como nas redes sociais tendemos a estar - por falar nisso, nunca pensaste um app para o MO_AND?). Este trabalho de sensibilização e fractalização da atenção, como dizes, distrai-se das intencionalidades do EU através da co-operação. $\mathrm{O}$ alinhamento dos corpos e dos afetos parece evidenciar uma atitude zen, na medida em que facilmente se está pronto a abandonar os estímulos teimosos do pensamento para entrar em fluxo com o processo de re-paragem com o outro, nesse comum que se vai fazendo. Como dizes (pegando na analogia anglo-saxónica de forgive e for give; forget e for get), é preciso desapegar (perdoar para dar) e desaprender (esquecer para ter, ao invés de ser), em ordem a "receber" (Eugénio 2017: 209) e entrar no metálogo - que resgatas de Bateson (1987) para sentir-pensar-fazer junto (Eugénio 2017: 209).

Gostaria ainda de conduzir a lupa para o contato daquilo que referes como uma sabedoria da liminaridade. Nesta propensão que o MO_AND tem de ativar a sensibilidade para outras faixas de frequência para além do modo operativo É, parece que o jogo elabora as condições para a construção de um corpo sem órgãos. Como nos sugere Deleuze e Guattari (1980), a partir de Artaud, a construção de um corpo sem órgãos necessita da destruição de um organismo. É um corpo de desejo mas contra o organismo. O organismo supõe uma organização dos órgãos que forma um obstáculo à intensificação da energia livre (como o modo operativo É, ou derivação em OU). Por isso, é um corpo que visa destruir o organismo e formar um corpo de sensação, resultado da transformação do corpo empírico (Gil 2008). A este nível imagino que para jogar seja necessário alguma dose de prudência. 
Neste jogar ao undercommons, de nos incompletarmo-nos uns aos outros, jogo de contaminação recíproca em que se investiga na prática o que podemos ou não juntos (Eugénio 2017: 208), há uma recusa em formular o commoning por pressuposição. Por outro lado, podemos aqui igualmente ver uma tática de resistência à força deglutinadora do capitalismo, sempre pronto para absorver potenciais commons, ou comuns, como forma de os mercantilizar. Não será, então, o MO_AND a possibilidade de imaginar coletivamente e de modo situado uma espécie de sociedade sem órgãos?

FERNANDA - Uma sociedade sem órgãos! Esta formulação soa muito interessante. Sim, parece-me que o AND, no seu esforço por tornar acessível à escala humana a fractalidade infinitesimal e a vibratilidade relacional que não param de constituir(-se) e reconstituir-(se) (n) os corpos, revela-os sensivelmente enquanto sociedades - cada posição é já multidão, cada um é muitos. O jogo com diversas escalas e materialidades permite acessar enquanto experiência direta aquilo que já sabemos talvez por abstração: que não há diferença (senão de recorte fractal) entre indivíduo e sociedade - e reciprocamente. Quantidades - num sentido quântico - estão a ser distribuídas e redistribuídas a cada encontro, e os agregados a que chamamos Um ou Todo(s) são resultantes parciais, contingentes, deste fazer e ser feito recíproco, in-terminável (sem fim e sem nome). A anarquia talvez seja, tão-somente, este tornar visível e sensível - esta desobviação ao nível da vivência - de um socius explicitamente tardiano: feito da "posse recíproca, de modos infinitamente variados, de todos por cada um" (Tarde 2003). Um juntos espraiado-disseminado, movente-relacional, provisório e nunca pré-existente à relação, ou menos ainda encompassador. Um comum transversal, que se faz por atravessamento e não por contorno. Jogar a esta "desorganização", confirmá-la, verificar que dela é feita aquilo a que chamamos "vida social" - não havendo vida que não o seja, afinal - opera a anarquia não porque a reivindique, mas porque a reconhece enquanto operatividade inevitável, contínua e ilimitada, que já e ainda lá está, e da qual a hierarquia é apenas um caso particular e excecional (inevitavelmente temporário, ainda que perversamente possa durar todo o nosso tempo biográfico) - do mesmo modo que, como costuma dizer o Eduardo (Viveiros de Castro com.pess.), "a identidade não passa de um caso particular da diferença”. Cada um destes conceitos-entitários, portanto, apanha num estado circunstancial e o prende para apreender, produzindo um efeito de estabilidade, de anterioridade, de verdade. A partir daí, passa a ser anárquico reconhecer, de novo e de novo, na experiência, que este efeito diz mais sobre o instrumento coletor e a política que o anima - no limite, uma necropolítica, como a enuncia Mbembe (2018) - do que sobre a matéria do vivido.

Criar espaços para experimentar sair da política entitária-fragmentária; para ensaiar e afinar uma capacidade de desfragmentação: isto é anárquico sob a condição de ser também e simultaneamente zen, uma vez que jogar performativamente a anarquia não desorganiza a sociedade sem junto desorganizar o indivíduo, na sua forma egóica predominante. Eis a operacionalização que te lembraste de citar, a do desapego e do desaprendizado: uma certa "menorização do Eu" (Deleuze 2010) vai emergindo como consequência inevitável desse testemunhar - assistir sem espectar - da impermanência das coisas.

Nos jogos matéricos exercitados no AND, a combinação do recurso à experiência direta e da convocação de uma modulação filigranar da atenção está, justamente, a serviço de dar corpo e visibilidade à impermanência do ente-fragmento, a permitir que se experimente a sua textura relacional e com-positiva, que se possa assim devolver sensibilidade ao seu caráter de agregado - ou ainda, constante e gerúndio agregando e dobradura. "Envelopamento" (Latour 2008) que, conquanto inevitável e necessário para operar concretamente qualquer acontecimento, jamais 
diz tudo, nem definitivamente, nem (ainda menos) substitutivamente ao próprio acontecimento.

Sair do fragmento e do discreto: do pensamento eficiente, que não pára de abordar o mundo para sistematicamente classificá-lo, enquadrá-lo, qualificá-lo, tirar dele o melhor proveito ou lucro. Despistar esta operação tão entranhada - a da racionalização, que parece dar as cartas de tudo o que a princípio conseguimos distinguir a olho nu - ou, a bem dizer, a "olho vestido" (muito bem vestido, afinal, com a cosmovisão moderna, com a conceção durkheimiana da sociedade, etc. e tal - até as roupagens mais contemporâneas, como a da "pós-verdade" ou a da "alta performance", por exemplo) - é o que talvez possa uma prática constante de descondicionamento da perceção. Uma que a sintonize com a escala da fractalidade, na qual se pode acompanhar o "ir sendo" (e não o "começar por ser") das coisas-pessoas-lugares.

Não raro, nesse aspeto, as práticas do AND são aproximadas e comparadas, por praticantes de diferentes procedências, à meditação de insight. O que se compara será talvez a sensibilidade operacionalizável através de ambas essas práticas, a despeito da sua imensa diferença em termos formais. Será talvez a sua ética, pois a sensibilidade à fractalidade das coisas, ou o treino de uma capacidade de desfragmentação, vai constituindo justo uma ética de suficiência. De fato, em tempos de elogio do excesso, será não apenas zen, mas anárquico, professar a suficiência!

Mas se trata, como antevês, de um jogo arriscado que demanda muita prudência. Jogar ao suficiente, sim, mas apenas suficientemente. Trata-se de um cuidado - talvez o mais importante - que se vai tornando mais e mais fundamental conforme essa pesquisa vai sendo sustentada na duração, e consiste em não permitir que o jogo se feche sobre si mesmo, levando-se demasiado a sério, acreditando de um modo totalizador em si próprio. Isso seria recair no fragmento e, no limite, fazer do E um É.

\section{OMO _ AND E O MÉTODO ETNOGRÁFICO}

RICARDO - Tenho uma questão final que diz respeito ao momento fundador do $\mathrm{MO}_{-}$ AND e ao seu futuro, às suas aplicações. Podemos dizer que a génese do MO_AND está no âmago do trabalho etnográfico antropológico, isto é, da vivência de encontros em determinado contexto como forma de observação participante. Este é o foco tanto do MO_AND como da etnografia. Num momento em que assistimos à contaminação do método etnográfico com outras metodologias artísticas, peço que nos contes como é que o MO_AND emerge do trabalho etnográfico - dás-lhes vários nomes: etnografia recíproca, performativa ou como performance situada (Duenha et al. 2016: 114) - mas não encontrei em lado algum o tipo de experiências de campo que estiveste envolvida para parar no encontro como acidente. Refiro-me aos contextos em que praticavas estes exercícios da atenção que vieram a dar o AND. Por outro lado, para finalizar, gostaria ainda que referisses as aplicações que tens experimentado com o MO_AND. Ele vem da etnografia. Sai, de alguma forma, do seu escopo, e o seu uso entra nas metodologias de improvisação e composição das artes da performance. E agora parece estar a ser devolvido à esfera das etnografias experimentais que estão a ser usadas por vários campos disciplinares. 
FERNANDA - Como fui parar no encontro como acidente? Olhando em retrospeto, tendo a reconhecer que o acidente é que veio ter comigo; ele é que veio cá parar! A inquietação dada por um imponderável que acaba por se fazer encontro impôs-se desde o primeiro campo mais denso que realizei, durante o mestrado, entre 2000 e 2001. Escolhi pesquisar a experiência do trauma e da reformulação de si com pessoas que tivessem perdido a visão já adultas, mas durante a frequentação quotidiana de um centro de reabilitação no Rio de Janeiro, vi-me seguidamente impedida de encontrá-las diretamente, pelo próprio funcionamento da instituição, que impunha sempre um mediador autorizado como guia e "tradutor" daquela experiência. Como se, ao perderem a visão, fosse também dada por perdida a sua capacidade de falar por si. Essa situação levou-me já na altura, em esboço, a entrever um Modo Operativo É a funcionar. E foi através de um acidente que, afinal, abriu-se a brecha para tocar - neste caso mesmo literalmente - a questão que moveria a minha pesquisa. Um atraso do diretor do centro de reabilitação, com quem teria uma reunião para autorizar a continuidade do campo, levou a sua secretária a sugerir, para passar o tempo enquanto o esperava, que eu fosse assistir a uma atividade da escola que também funcionava na mesma instituição. Vieram ter comigo várias crianças e em minutos deu-se o encontro não-mediado que havia buscado por meses. Transferi a pesquisa para o setor da "alfabetização especial" e lá se foi: emergiu uma pesquisa das imbricações entre corporeidade, aprendizado de si e do entorno, autonomia e letramento com crianças portadoras de diversas gradações de invisualidade que, afinal, me escolheu a mim (Eugenio 2002). Nesta altura o meu então orientador, Luiz Fernando Dias Duarte (com.pess.), sintetizou a força deste acidente sugerindo-me explorar a máxima de que a etnografia "dá certo mesmo quando dá errado".

Foi o que fiz, e parte da escrita ocupou-se de extrair as consequências deste episódio para descrever um tipo de sensibilidade investigativa que se inaugura com o acidente, a etnografia. Demorar no acidente, aceitando para isso mudar de questão, envolvia não empurrar rápido demais, como de solito, uma matéria como esta ao espaço da anedota - aquela que é contada geralmente nas introduções, servindo para alimentar a narrativa romanceada sobre as aventuras do antropólogo em campo, e a seguir deixada de lado quando o trabalho dito sério - "interpretar o outro" - se inicia.

Esse esforço descritivo dos procedimentos sensíveis da etnografia - e que começavam a enunciá-la como um jogo entre o desencontro e o encontro, no qual tanto o território, quanto os agentes, quanto (e sobretudo) a questão a ser tratada, estavam por emergir de uma colisão inesperada e do compromisso por seguir com ela, desdobrá-la e ficar a saber, se calhar, só no fim - foi desdobrado na sequência durante os anos em que me tornei professora de uma disciplina introdutória à antropologia, dada a alunos de graduação. Desviando da ementa sugerida, estritamente teórica, considerei que não havia outro modo de "ensinar" antropologia que não fosse através do convite a performá-la. A jogar com as suas ferramentas, entrando no domínio de uma sensibilidade particular - sensibilidade a esta colisão que estaria sempre na iminência de acontecer, carregando-nos por contágio sintónico com o alheio, e assim abrindo possibilidade para a invenção de uma reciprocidade. Nestes anos surgiu a primeira proposição da etnografia como jogo, que envolvia duas fases: a primeira consistia em contornar a tentação de "escolher um tema" e abrir espaço para "ser encontrado pela questão"; a segunda, em procurar sistematicamente, ao escrever-viver a experiência, deslocar o relato da tendencial esfera do "porque" para a esfera do "como".

A formulação do AND (na altura dito "modo de vida E”) veio entretanto somente durante o campo do doutoramento (2002-2005), e mais uma vez através de uma sequência de acidentes 
que me foram encontrando e, ao mesmo tempo, circunscrevendo o campo de inquietação da pesquisa, que acabou por se tratar dos relacionamentos erótico-afetivos e de amizade vividos no circuito daquela que, na altura, era chamada de "cena eletrónica carioca" (Eugenio 2006). Nesta pesquisa, tanto território como agentes eram difusos, disseminados, fugidios se se os tentava agarrar com os conceitos prediletos da antropologia - cultura ou identidade. Eram modos de explorar o que podem os corpos, juntos em quase todo e qualquer arranjo, que apareciam no cruzamento imprevisível e a cada vez re-situado de várias linhas de força (uma certa relação com a música, com o uso de substâncias sintéticas, com as tecnologias digitais, com a moda, com espaços urbanos intervalares, com o mundo do trabalho, etc.), não sendo nunca suficientemente descritos por nenhuma delas em particular - e que, reciprocamente, co-participavam também no desenho em movimento de cada uma dessas linhas de força. Os anos de pesquisa co-incidiram com o espaço-tempo dos anos em que, no Brasil e em particular no Rio de Janeiro, as táticas daquilo a que eu viria a chamar de des-cisão (o desfazer da cisão moderna) concentravam-se numa fuga ao nome, justo na "curva da espiral" imediatamente anterior à atual (e correspondente, pois será o mesmo E, apenas com outra direção), cuja tendência é, agora, à implosão do nome por multiplicação, pela operação "trans", chegando talvez a nomear até o sem nome, a borda e o fora de campo, como o não-binarismo de gênero (ou o não-não-binarismo!), a tensão assexualidade/panssexualidade, ou ainda, de outro modo, a tensão entre a monogamia e o poliamor e entre este e o anarquismo relacional.

Essa pesquisa não parou de sofrer acidentes até aceitar instalar-se no próprio problema de nunca saber do que estava a tratar, restando então quase que apenas o seu exercício enquanto continuado (re)performar do encontro, inevitavelmente etnográfico e auto-etnográfico: em relação, rastrear o refazer das relações entre as relações. Eis a primeira formulação explícita do E/AND. A sustentação de um estado de fervura in-terminável rendeu uma reformulação - e um agravamento radical assumido a partir de então - da máxima que me havia sido sugerida anos antes no mestrado: já não se tratava de uma etnografia que "dá certo até mesmo quando dá errado", mas de uma etnografia - como então me foi re-proposto pelo orientador do doutoramento, Eduardo Viveiros de Castro (com.pess.) - que "só dá certo se der errado". Trazendo esta memória para o presente desta conversa, parece-me que este é um enunciado suficiente e preciso da sabedoria da liminaridade!

Assumir esta errância do sentido - o nonsense, lá está - como condição disparadora de uma etnografia recíproca levou-me (a este ponto, já sem pretensão alguma de saber por antecipação no que isso iria dar) a reatar a relação com o campo da dança e da performance apenas findo o doutoramento, em 2006. Precisava - e aí encontrei essa possibilidade - de experimentar o que podia esta etnografia que tinha tomado corpo de corpo; precisava de experimentar com outras interfaces que não a do texto, e sobretudo, precisava de experimentar esta etnografia como um fazer radicalmente coletivo: no limite, inventar o próprio campo, nunca diretamente, mas como consequência de ir inventando aqueles com quem se vai encontrando, e ir se deixando inventar por eles, fazendo dos conceitos, ferramentas (daqueles que resistissem à experiência vivida, e daqueles dela emergentes). Precisava de me demorar (e eventualmente, de jamais sair) do estado de encontro performativo-etnográfico, fortalecendo modos de fazer "consistência" para desviar do imperativo da coerência no qual se deve construir o diagnóstico analítico-interpretativo. Estas experimentações começaram por trabalhar com a materialidade da rua e do caminhar, já que era de errância à escala do corpo que se tratava. O jogo da passagem do "porque" ao "como", que havia criado na relação com os meus alunos de graduação, se foi desdobrando em todo um 
sistema para a cartografia em movimento das relações a partir das coordenadas interrogativas situadas que-como-quando-onde, que até hoje estão presentes no AND.

Esta foi a Etnografia como Performance Situada, que de certo modo operou a passagem entre a formulação inicial do AND ainda no âmbito da antropologia académica e uma sua primeira derivação para o campo da performance. Deu um uso dirigido às errâncias urbanas que comecei a fazer ainda entre 2004 e 2005, no doutoramento, na altura como tática de rastreamento daquele desenho territorial instável, em circuito sempre cambiante. A partir de 2006, acrescentou-se a este procedimento um uso deliberado da circunscrição etnográfica na operacionalização de proposições artísticas situadas, num esforço de deslocamento da sensibilidade e do fazer etnográficos para um plano de uso comum e coletivo, abordando-os como instrumentos para o jogo de com-posição relacional em escala humana e para a performance ao vivo do encontro. Funcionava (e ainda funciona; agora esta investigação continua sob a forma de uma das linhas de investigação do AND Lab) assim: a partir da instalação de uma zona comum de atenção num território da cidade, trabalhava com diferentes cortes fractais de matéria urbana, mapeando os funcionamentos urbanos emergentes das relações entre geografia, arquitetura, uso e habitação, inventariando as brechas e os encaixes propiciados (ou não) pelas gradações público-privado e próximo-distante, e pelas variadas relações-tensão entre o coexistir e o conviver. Através desta prática, ia extraindo da própria materialidade do quotidiano os nexos relacionais, as questões e as interfaces a serem manuseados a seguir na construção de jogos, proposições e performances do/no lugar.

Neste período, comecei a dar aulas em cursos técnicos de dança, sem deixar os meus alunos da graduação em Ciências Sociais. Além disso, também a colaboração com o artista contextual Gustavo Ciríaco (iniciada em 2007 e continuada até hoje nos projetos Práticas Site-Specific e City Labs) foi importante para dar forma ao percurso que se ia construindo. Esses dois espaços de encontro tornaram explícita uma crescente necessidade/vontade de partilha de procedimentos e estimularam a sistematização da pesquisa sob a forma de caixa de ferramentas: um conjunto de proposições percetivas para experimentar (com) o lugar, explorando os recursos simples do andar e do parar num convite à demora etnográfica enquanto Reparagem - via de investigação da performatividade já manifesta na vida quotidiana - e, a seguir, no trabalho com a matéria emergente a partir do Reprograma - jogo no qual o percorrer recursivo dos Mapas do Quê-Como-Quando-Onde leva, por derivação e consequência, a uma proposição situada, sintetizada numa única frase-força ou força-tarefa, a ser vivida e, então, consecutivamente reprogramada, num compromisso continuado de afinação com o lugar e o que já lá havia, em latência, para a performance do encontro.

Mais adiante, em 2009, emergiu a colaboração com o João Fiadeiro e o seu método da Composição em Tempo Real, que acabou por me trazer a Portugal. Entre 2011 e 2012 organizamos o AND Lab sob a forma de um projeto de etnografia recíproca dos nossos procedimentos. Em paralelo, foram dois anos em que, através de um pós-doutoramento no ICS/UL (Eugenio 2010), formalizei o AND já muito próximo da forma atual. Durante os anos dessa colaboração, que se estendeu até 2013 (Eugenio e Fiadeiro 2012, 2013), a Etnografia como Performance Situada acabou por assumir o nome Modo Operativo AND, ao qual se incorporaram também exercícios de improvisação em estúdio que inventamos juntos, como a escala do tabuleiro, com a qual hoje em dia costumo começar a partilha - que depois percorre diferentes escalas até ser "devolvida" ao plano de uma aplicação na vida quotidiana. Com todas as variações, interlocuções e bem-vindos encontros-acidentes com pessoas e lugares, a estrutura de base dessa longa 
investigação é, entretanto, mais ou menos a mesma desde o início, envolvendo as zonas da Reparagem (Deambulação e Paragem) e do Reprograma (Trabalho de Mapas, Circunscrição, Enunciação e Imaginação). Nos anos a seguir, e até ao presente, o AND Lab passou de projeto a lugar - foi formalizado como plataforma de pesquisa e como associação cultural, mais ou menos ao mesmo tempo em que o Modo Operativo AND foi assumindo a sua dimensão ético-política forte e o seu compromisso com a reparação diante do Irreparável que é o mundo. De 2014-15 em diante - e este será talvez o maior dos acidentes, nunca o teria imaginado! - o MO_AND se foi tornando mais e mais transversal, sendo adotado por investigadores das mais diversas áreas para pensar e praticar o comum. Além da dança, do teatro, da performance e das artes visuais, que foram os primeiros encontros na derivação para fora da academia, surgiram colaborações ou pesquisas autónomas (pessoas a fazer mestrados e doutoramentos, ou projetos de intervenção e aplicação, em diferentes países) com áreas tão diversas quanto pedagogia, mediação cultural, serviço social, arquitetura e urbanismo, psicologia transdisciplinar e até mesmo informática, no âmbito da qual - e para responder à pergunta que me fizeste de passagem na questão anterior - efetivamente foi criado, por um estudante de mestrado na área de Interação Humano-Computador, um And App, atualmente em fase de testes. Resumidamente, aí está um pouco do percurso de como se foi gestando - e agora espalhando - este jogo de sensibilização ao acidente que é o AND.

\section{CONCLUSÃO}

FERNANDA - Porque é que o AND é um jogo?

RICARDO - As tuas respostas em cima justificam já o AND como jogo, e um jogo que se deve até jogar na vida. Falas na sua estrutura, explicas as várias fases do seu desenvolvimento e a experiência desse jogar, abordando inclusive a sua política. Para finalizar, eu diria apenas que o modo operativo AND é um jogo dionisíaco que Apollo gostaria de assistir.

\section{BiBLIOGRAFIA}

Agamben, Giorgio. 2007. Profanations. New York: Zone Books.

Barthes, Roland.2003. Como viver junto. Simulaçóes romanescas de alguns espaços cotidianos. Cursos e seminários no Collège de France 1976-1977. Texto estabelecido, anotado e apresentado por Claude Coste. São Paulo: Martas Fontes.

Bateson, Gregory. 1987. Steps to an Ecology of Mind: Collected Essays in Anthropology, Psychiatry, Evolution, and Epistemology. Northvale, New Jersey, London: Jason Aronson Inc.

Bernardo, Gustavo. 2011. "Dois menos um pedacinho." Pp. 7-19 em A Dúvida, Vilém Flusser. São Paulo: Anna Blume.

Certeau, Michel de. 1998 (1990). A Invenção do Cotidiano. Petrópolis: Editora Vozes.

Deleuze, Gilles. 2007. Francis Bacon: Lógica da Sensação. Rio de Janeiro: J. Zahar. 2010. "Um manifesto de menos". Pp. 25-64 em Sobre o teatro: Um Manifesto Menos. Rio de Janeiro: Zahar.

Deleuze, Gilles; Guattari, Felix. 1980. Milles plateaux. Paris: Minuit. 
Duenha, Milene Lopes; Fernanda Eugenio and Ana Dinger. 2016. "Entre-modos. Um jogo de re-perguntas à volta do Modo Operativo AND." Urdimento Revista de Artes Cênicas, 2 (27) (Dezembro): 96-123.

Eugenio, Fernanda. 2002. Crianças Cegas. Uma etnografia das classes de alfabetização do Instituto Benjamin Constant. Dissertação de mestrado. Orientação: Luiz Fernando Dias Duarte. Rio de Janeiro: PPGAS, Museu Nacional.

. 2006. Hedonismo Competente. Antropologia de urbanos afetos. Tese de doutoramento.

Orientação: Eduardo Viveiros de Castro. Rio de Janeiro: PPGAS, Museu Nacional. 2010. Manifesto AND. Um outro mundo possível, a secalbaridade. (Das relações entre a Etnografia Reciproca e a Filosofia do Acontecimento). Projeto (Pós-Doutorado) - Instituto de Ciências Sociais, Universidade de Lisboa. 2012. "O encontro é uma ferida". Lisboa: Ghost Editores. . 2017. "Por uma política do co-passionamento: comunidade e corporeidade no Modo Operativo AND”. Fractal, Revista de Psicologia, 29 (2): 203-210. . 2018. "Para uma situ-ação do Modo Operativo AND". And Doc, Acervo Digital do AND Lab. Disponível em https://www.and-lab.org/para-uma-situ-acao-do-mo-and.

Gadamer, Hans-Georg. 1999. "A Ontologia da Obra de Arte e seu Significado Hermenêutico.” Pp. 174-269 em Verdade e Método: Traços Fundamentais de uma Hermenêutica Filosófica, editado por H. Gadamer. Petropólis, Rio de Janeiro: Editora Vozes.

Gil, José. 2008. O Imperceptivel Devir da Imanência: Sobre a Filosofia de Deleuze. Lisboa: Relógio d’Água, Colecção Filosofia.

Jullien, François. 2000. Um Sábio não tem idéia. São Paulo: Martins Fontes.

Latour, Bruno. 2005. Reassembling the social: an introduction to Actor-Network-Theory. New York: Oxford University Press.

. 2008. "A cautious Prometheus? A few steps towards a philosophy of design (with a special attention to Peter Sloterdijk).” Keynote lecture, Seminário Networks of Design. Cornwall. Disponível em <http://www.bruno-latour.fr/sites/default/files/112-DESIGN-CORNWALL-GB.pdf $>$.

Mbembe, Achille. 2018. Necropolitica. Biopoder, soberania, politica de exceção, politica da morte. São Paulo: N-1 edições.

Sewell, Elizabeth. 2015. The Field of Nonsense. Victoria, London, Dublin: Dalkey Archive Press. Stewart, Susan A.. 1989. Nonsense: Aspects of Intertextuality in Folklore and Literature. Baltimore, London: The Johns Hopkins University Press.

Sutton-Smith, Brian. 2001. The Ambiguity of Play. Cambridge, Massachusetts, London: Harvard University Press.

Tarde, Gabriel. 2003. Monadologia e Sociologia. Petrópolis: Vozes.

Viveiros de Castro, Eduardo. 2002. “O nativo relativo”. Mana, 8 (1): 113-148.

\section{IS AND A GAME? AN ESSAY-CONVERSATION ON THE OPERABILITY OF PLAY IN MODUS OPERANDI AND}

Modus Operandi AND (MO_AND) is a system of improvisation and co-positioning that offers a
series of tools for a practical study of the politics of togetherness and the development of in-act self-ob-
servation and situational position-taking skills. Within MO_AND, the (counter)apparatus of the
non-competitive play is used as a "simulator of accidents". Working with scales of menorization/max-
imization of the (in)visible and of reduction/enlargement of time and space, the AND game allows to 
train attention to the common as well as an availability to the unforeseen and a rejoicing for community. The game works as an invitation for an experiential investigation of the fold-and-unfold-like functionment of the Event, either through assisting its spirals of emergence and exhaustion, or through direct handling its propagation in immanent and always provisional rules. In this essay-conversation, Ricardo Seiça Salgado - based on his research on the procedures and effects of performative play with(in) ethnography - and Fernanda Eugenio - who has been developing MO_AND in a trajectory of reciprocal contamination between anthropology and performance - try to navigate the landscape of issues raised by this on-going research, putting in perspective its legacy and potency as play/game.

Keywords: modus operandi AND, play/game, nonsense, ethnography, commons, ethics of sufficiency

Recebido em: 2018-04-06

Aceitado em: 2018-06-14 